\title{
Subjective assessment of the working conditions of teachers, administrative staff and students at Russian State Social University
}

\author{
Elena Petrova ${ }^{1, *}$, Irina Sokolovskaya ${ }^{1}$, Angela Romanova $^{1}$, Svetlana Tereshchuk $^{1}$ \\ ${ }^{1}$ Russian State Social University, Russia
}

\begin{abstract}
The relevance of the work lies in the relationship between the concepts of satisfaction with the conditions of professional activity and the subjective assessment of the working conditions of teachers, administration and teaching at the Russian State Social University (RSSU). Further behavior, mood, motivation for effective work or study depend on satisfaction with the conditions of professional activity and place of work or study. This assessment may suggest a negative flow of impressions, which could have a detrimental effect on the image of the RSSU.
\end{abstract}

\section{Introduction}

As studies of labor activity show, the satisfaction of working conditions is the most important but controversial factor in increasing productivity and labor efficiency. A decrease in satisfaction with one's own work negatively affects the efficiency of teachers, administration and students, leading to negative consequences in staffing of a system: facts of staff turnover, deterioration of discipline, psychosomatic diseases, and facts of neglect of property.

Thus, satisfaction with working conditions of teachers, administration and students should consist of the following criteria: subjective assessment, health and good manner.

Administrative staff of an educational organization is at the forefront of communication process with various groups of workers, students and parents, therefore health of administrative staff of the university is an important factor.

The unfavorable factors of labor activity, leading to occurrence of professionally determined health disorders in administration of a Higher Educational Institution, include physical, mental and emotional overload.

For example, during the period of self-isolation, an increase in psychosomatic disorders was noted, which is due to the presence of significant mental and emotional stress during work, leading to depletion of the nervous system with the subsequent development of the socalled emotional burnout syndrome.

The main unfavorable factor in the labor activity of the university administration, which influences their state of health, is high mental and emotional stress.

\footnotetext{
* Corresponding author: petrova-sorina@yandex.ru
} 
Intensity of workloads in combination with the unfavorable influence of the factors of the labor process (being forced to be at the workplace) leads to appearance of signs of occupational fatigue.

\section{Main material}

Job satisfaction is the assessment of conditions, process and work result by personnel. It can be positioned between "totally liked" and "completely disliked". Everyone knows very well that the efficiency of staff work depends on the level of satisfaction.

Effective pedagogical activity is determined by a mission of an educational institution, goals and objectives arising from the mission, which characterize its uniqueness. The mission of an educational institution is determined by the set of basic values of the organization of the pedagogical process and indicates their features. Different schools may vary in their missions; this process is associated with their management, teachers of a school, and other employees' attitude to a designation of an educational institution.

The teacher's dissatisfaction with their work in a particular educational institution is usually determined by principles of assessing pedagogical activity or working conditions; relations in teaching staff are of great importance.

Decreased satisfaction inevitably leads to a drop in productivity. The unwillingness to work can be manifested in: lateness; conflicts at work; actions that harm the organization; change of workplace; irritability; many other things.

In order to prevent this behavior, you need to know what influences employees' satisfaction.

Lets view the main factors:

- Content of the work. Promising, demanding dedication, interesting work, with probability of success contributes to an increase in employee's satisfaction; and vice versa, boring, monotonous, and repetitive activities reduce satisfaction.

- $\quad$ Physical working conditions (temperature, light, noise, etc.). The better they are, the more satisfied subordinates will be.

- Characteristics of a subordinate. The higher their educational level and self-esteem of an employee is, the higher is their satisfaction. Also the work that corresponds to abilities of a person brings more satisfaction.

- Social environment.

- A well-organized management system of an educational institution.

- Salary (timeliness, validity, etc.).

- Opportunity for learning and development.

To increase motivation of administrative staff, all of the above factors must be considered.

Satisfaction with working conditions is an important indicator of loyalty. This factor includes everything on which the ecology and ergonomics of the workplace depend: availability of necessary tools, their convenient placement, thoughtful lighting, and quality of drinking water used in offices and classrooms, and the like. From an employee's point of view, satisfactory nature and conditions of work are the main indicators of a manager's authority. For most workers, the best management is the one that is able to improve conditions for their work. Efficiency of activity is the cause of satisfaction with the content of labor and a consequence of satisfaction with working conditions and material rewards.

The famous American social psychologist Frederick Herzberg analyzed causes of people's dissatisfaction with their work and identified the factors that can influence the interest in work. F. Herzberg, in his motivational theory, divides the factors that affect obtaining satisfaction from work into two directions: 
The psychologist classifies hygienic factors to the first group of factors. According to F. Herzberg these factors include wages, interpersonal relationships in a teaching staff, activities carried out by administration of an educational organization, their control over professional activities of teachers and students, and also comfort of workplaces [1].

F. Herzberg believes that hygienic factors do not affect the motivation of work, at the same time, if they are low or absent, they may result in job dissatisfaction. Conflicts in a teaching staff will not contribute to introduction of innovations in the teaching process or the teacher's self-improvement. At the same time, according to F. Herzberg's theory of motivation, successful improvement of hygienic factors by the administration of an educational institution will not be a certain incentive that will direct teachers to effective work, which in itself will bring everyone satisfaction in their pedagogical activities. Good administration work can provide a comfortable moral and psychological climate within a particular organization. This will be facilitated by creation of conditions for teachers' work by equipping classrooms with good furniture, useful for both teacher and students. Equipment of rest rooms and psychological relief rooms will help teachers feel comfortable. However, according to F. Herzberg's theory, we can say with confidence that all the above factors will not be able to make teachers work effectively and will not increase their satisfaction with their pedagogical activities. The same can be said about bonuses, which are paid in the amount of $20 \%$ of the salary, taking into account F. Taylor's definition that the quality of work can be improved only by a bonus of at least $30 \%$ [1].

The psychological factors of satisfaction with working conditions include:

- $\quad$ Age factor, when older teachers become absorbed in their work.

- An experienced teacher needs professional growth and self-development.

- Loyalty to the profession and belief in professional ethics.

- $\quad$ Trust and respect in the team

- A positive assessment of a teacher's work by their colleagues and management of an educational institution, as well as by students and trainees.

- Ability to see a result of their work and evaluate it.

- Feedback from students.

- Work in harmony with their team, adherence to corporate ethics.

Influence of workers's age on the level of job satisfaction.

The degree of an employee's satisfaction with their work is greatly influenced by their age. Satisfaction with work in the age range from 20 to 30 years is reduced due to discrepancy between conceived plans of a young person in relation to his/her activities in the labor field or career growth in a certain position and realities of life in which that employee finds him or herself, - "state of shock pursuant to confrontation with reality" [2].

But over time, the employee somehow gets used to and adapts to this and even reaches certain professional goals. At the same time, his/her satisfaction gradually increases. Its highest take-off point is closer to 40 years old. The take-off is followed by a "mid-career crisis", which is observed in the 45-50 age group. After successful resolution of this crisis state, the level of satisfaction again goes up, but begins to decline steadily as soon as the employee enters the pre-retirement age.

Emotional satisfaction of administrative staff. The presence of an attitude that forms in the mind of an administrative employee an attitude to their performed activity has features of an emotional nature associated with subjective experience of significance of job satisfaction in the general range of life activity. To a fairly strong degree, the emotional attitude to job satisfaction determines behavior strategies of administrative workers in stressful situations.

Among the factors of job satisfaction, a special place is occupied by the subjective assessment of success of professional activity, which is manifested by a specific mindset of an individual, his/her attitude to a kind, volume and quality of work he/she performed. An administrative worker emotionally experiences their professional environment as a source of 
achievements, contributing to formation of their belief in possibilities of their own influence on results of their work [2].

Positive emotional experiences associated with assessment of the environment of activity can become a powerful factor in development of an individual's stress resistance, creating a kind of protective shield for a working employee.

In other words, positive emotional satisfaction with work can be considered as a factor influencing on feeling of professional success and high psychophysical condition of an employee.

At the same time, a low level of job satisfaction can be considered as one of the factors affecting decline in staff productivity. Provided that an administrative employee's satisfaction with the results of their work has an emotionally negative connotation, as a result, it creates a threat to their mental and physical health [2].

F. Herzberg called motivating the factors that could activate professional skills of teachers, and thus stimulate satisfaction with working conditions. The essence of the factors lies in the fact that they allow a teacher to achieve recognition and respect among colleagues and students at their workplace, in their teaching staff. With the help of motivation factors, a teacher will be able to satisfy their cognitive and aesthetic needs, which they will subsequently pass on to their students. Motivating factors will help to realize vast possibilities of any person, and in our case, a teacher in the course of their work [3].

The factors noted by F. Herzberg as motivating ones include creative and professional growth, achievement of success in teaching, recognition of fruits of one's teaching activity and approval from colleagues and administration, professional advancement, responsibility for their activities. Remuneration, which is an indicator of the result, will also be considered as a motivating factor and a factor of satisfaction with one's activities [3].

To our great regret, in academic staffs there is a situation when teachers can be satisfied with such a situation when they do not need to be responsible for anything. In such cases, teachers are not interested in innovative teaching methods and they enjoy doing routine work without thinking about creativity. Therefore, it is impossible to say with complete confidence that the absence or lack of motivating factors in pedagogical activity must certainly lead to dissatisfaction with pedagogical activity [4,5]. Many teachers are satisfied only with the social side: work is close to home, work regime, workplace comfort, comfortable conditions in a teaching staff. Such teachers can get satisfaction from the fact that no one scolds them, even if no one praises them. Such satisfaction with pedagogical activity can and does satisfy teachers themselves, but in no way can it satisfy the pedagogical process that should be carried out in an educational institution.

Thus, it can be concluded that hygienic factors can influence satisfaction of teachers and administrative staff with their professional activities. Motivating factors influence effective achievement of general goals of an educational institution and stimulate personal goals of both a teacher and an administrative employee, thereby forming satisfaction with professional activities.

\section{Research methods}

Purpose of the work: Subjective assessment of satisfaction with the working conditions of teachers, administrative staff and students of the Russian State Social University.

This goal requires solving the following tasks:

1. To identify the socio-psychological factors affecting the subjective assessment of the working conditions of teachers, administrative staff and students of RSSU.

2. To develop a diagnostic complex aimed at identifying social and psychological factors of satisfaction with conditions of professional work. 
3. Conduct and analyze the results of monitoring to identify socio-psychological factors affecting the subjective assessment of satisfaction with working conditions among teachers, administrative staff and students of RSSU.

4. To develop methodological recommendations for increasing the level of satisfaction with working conditions among teachers, administrative staff and students of the RSSU.

Work hypothesis: the level of satisfaction with the work of teachers, administrative staff and students of RSSU is influenced by the following social and psychological factors characterizing the subjective assessment of well-being: interest in work, satisfaction with work achievements, microclimate in the team, level of aspirations in professional activity, tension in a labor process, satisfaction with working conditions, level of professional responsibility, wages, adaptability, possibility of further development.

The research base is represented by a wide range of materials that can be divided into several groups.

The first is the theory of motivation and job satisfaction by F. Herzberg, F. Taylor, D. McClelland.

The second group of the research base includes the methods used in the research. The following methods were used to collect empirical material: the author's questionnaire for subjective assessment of job satisfaction, the method "Integral Job Satisfaction" by A.V. Batarshev, the source is Fetiskin N.P., Kozlov V.V., Manuylov G.M. The scale of subjective well-being (Échelle pour l'évaluation subjective du Bien-être) was developed by the French psychologist A. Perué-Badoux and colleagues (A. Perrudet-Badoux, G. Mendelsohn, J. Chiche) in 1988. The author of the Russian-language adaptation is M.V. Sokolova; Diagnostics of Personal and Group Job Satisfaction / Fetiskin N.P., Kozlov V.V., Manuilov G.M.

The third group of the research base consisted of the collected empirical materials on the conducted research and their subsequent analysis.

Characteristics of the research base. The study was based on teachers, administration and students of the Russian State Social University (RSSU) in Moscow. The study involved 1550 teachers, administrative staff and students. The age of the subjects was from 20 to 65 years old.

\section{Results and discussion}

Social factors were identified that affect the subjective assessment of satisfaction with the working conditions of teachers, administrative staff and students of the RSSU.

Social factors of satisfaction with the working conditions of teachers and administrative staff include:

1. Content of work.

2. Physical working conditions (temperature, light, noise, etc.). The better they are, the more satisfied the subordinates will be.

3. Social environment.

4. A well-organized management system in an educational organization (quality management system) contributes to an increase in employee's satisfaction.

5. An important factor is earning.

6. Learning and development opportunities increase job satisfaction.

Psychological factors of job satisfaction are:

1. Age factor, when aged teachers become engaged in their work.

2. An experienced teacher has a need in professional growth and self-development.

3. Loyalty to the profession and belief in the professional ethic.

4. Confidence and respect in the team. 
5. Positive assessment of a teacher's work by their collegues and management of an educational institute, and also by their students.

6. Possibility to see a result of their work and evaluate it.

7. Feedback with students.

8. Work in harmony with collegues, observation of corporate ethic.

Hygiene factors can influence satisfaction of teachers and administrative staff with their professional activities. Motivating factors influence effective achievement of the overall goals of the educational institution and stimulate personal goals of teachers and administrative staff, thereby forming satisfaction with professional activities.

Analysis of the monitoring results to identify social and psychological factors of satisfaction with the working conditions of teachers (teaching staff/TS), administrative staff (AS) and students (S) of the RSSU showed that the majority of TS (51\%) have a low severity of subjective well-being / distress: persons with such assessments are characterized by moderate subjective well-being, they have no serious problems, but one cannot speak of their complete emotional comfort. At the same time, the majority (45.3\%) have a low level of overall job satisfaction. If the analysis is carried out according to the scales, then we can note an insufficiently high interest in work and some dissatisfaction when communicating with the leadership of the educational organization. At the same time, only $63.3 \%$ of teachers (TS) are satisfied with their work, $58.3 \%$ of administrative employees (AS) are quite satisfied with their work, $(46.6 \%)$ in the group of students (S) are satisfied with their work. For these groups, we can single out the average trend towards job satisfaction, presented in Table 1.

Table 1. The level of satisfaction with working conditions and subjective well-being of teachers (TS), administration (AS) and students (S) RSSU.

\begin{tabular}{|c|c|c|c|c|}
\hline Well-being factors & TS. \% & AS.\% & S.\% & $\begin{array}{c}\text { Overall results of job } \\
\text { satisfaction }\end{array}$ \\
\hline Hygienic & 51 & 45 & 40 & $\begin{array}{c}45.3 \\
\text { (low level) }\end{array}$ \\
\hline Psychological & 60 & 75 & 60 & $\begin{array}{c}67 \\
\text { (high level) }\end{array}$ \\
\hline Social & 75 & 55 & 40 & $\begin{array}{c}56.6 \\
\text { (average level) }\end{array}$ \\
\hline $\begin{array}{c}\text { Average value for } \\
\text { groups. subjects }\end{array}$ & 63.3 & 58.3 & 46.6 & $\begin{array}{c}\text { Average level of } \\
\text { satisfaction }\end{array}$ \\
\hline
\end{tabular}

Thus, when studying all parameters of job satisfaction and subjective well-being, we saw that in the group, the majority of TS and AS have an average and low level of subjective well-being and an average and low level of integral characteristics of job satisfaction, an average and low level of job satisfaction. Such data indicate a relationship between subjective well-being and job satisfaction.

In order for the teacher of an educational institution to feel satisfied with their teaching activities, it is necessary to create such conditions in the organization so that the teacher feels success in their work; this factor will stimulate a creative approach to teaching. Recognition of the teacher and his/her activities can be carried out with the help of students and their surrounding society, availability of opportunities for creative activity and development. An important factor for the teacher's feeling of satisfaction with their teaching activities is understanding of usefulness and significance of their work. Teachers get satisfaction with their work if they see success of their students, feel themselves recognized in their professional teaching community. 
If you focus only on F. Herzberg's theory, then you can see some inconsistencies when applied to teachers. One and the same factor can generate enthusiasm at work, create a sense of satisfaction for one teacher, and for another one, can cause feelings of dissatisfaction with their work. For example, teaching at graduation courses for one teacher is a fact of recognition, responsibility and, as a result of graduation, satisfaction with their teaching activities. While for another teacher, all the listed work will be unnecessary worries and routine work. However, this example should not be regarded as a common practice, but rather as a deviation.

\section{Acknowledgment}

This publication has been prepared with the financial support of the Russian State Social University. Registration number of the research project at the expense of the Russian State Social University (RSSU) is № 604-06/20 “Conducting a study to identify the subjective assessment of working conditions by teachers, administrative staff and students using the questionnaire method."

\section{References}

1. V.K. Gorbachevsky, Motivation and level of personality claims: Psychological methods (L., 2014)

2. G.R. Latfullin, A.V. Raichenko, Organization theory: Textbook (Yurayt, M., 2013)

3. V.N. Parakhina, T.M. Fedorenko, E.Yu. Shatskaya, Organization theory: Textbook (KnoRus, M., 2014)

4. E.A. Petrova, I.E. Sokolovskaya, N.N. Akimova, A.V. Romanova, Education and Science 22(2), 98-120 (2020)

5. I.E. Sokolovskaya, Digital Sociology 3(2), $46-54$ (2020) 